\title{
LA TRAYECTORIA DE LA ANTROPOLOGÍA \\ EN CHILE
}

The route of anthropology in Chile JOSÉ BENGOA *

\section{Resumen}

Este trabajo se basa en los contenidos de un curso dictado en la Escuela de Antropología de la Universidad Academia de Humanismo Cristiano, cuyo objeto es comprender desde una perspectiva crítica, la trayectoria de la antropología en Chile y sus aportes al conjunto de las ciencias sociales y la cultura de nuestra sociedad. Siguiendo una tesis crítica, se observa el carácter profundamente conservador que ha tenido la antropología en nuestro país y se aboga por una antropología crítica. Para dar cuenta de dicha tesis, el artículo pone especial énfasis en los precursores de la disciplina, así como en sus vínculos con ciertos postulados teóricos, distinguiendo además los grandes temas nacionales que configuraron la emergencia y consolidación tardía de la antropología chilena.

Palabras Clave: Antropología chilena, Historia de la antropología en Chile, Antropología crítica

\section{Abstract}

This work is based on the contents of a course taught at the School of Anthropology at the Universidad Academia de Humanismo Cristiano, whose purpose is to know the history of anthropology in Chile, and understand their contributions to the whole of the social sciences, and culture of our society. The argument sustained is that anthopology in Chile has been deeply conservative, so the need of a critical anthropology, is observed. To account for this thesis, the article puts special enfasis on the precursors of the discipline and its links with certain theoretical postulates, beside with distinguish the major national issues that shaped the emergence and consolidation of Chilean anthropology, although tardily.

Key words: Chilean anthropology, History of Chilean anthropology, Critical anthropology

\footnotetext{
* Rector Universidad Academia de Humanismo Cristiano (UAHC). Fundador y profesor de la Escuela de Antropología de la UAHC. Investigador Asociado del Centro Interdisciplinario de Estudios Interculturales e Indígenas-ICIIS/ CONICYT/FONDAP/15110006. Correo electrónico: jbengoa@academia.cl
} 


\section{Introducción ${ }^{1}$}

Durante casi dos décadas hemos dictado un curso en la Escuela de Antropología de la Universidad Academia de Humanismo Cristiano, cuyo objeto es comprender la trayectoria de la antropología en Chile y sus aportes al conjunto de las ciencias sociales y la cultura de nuestra sociedad. Es un curso crítico en la medida que trata de responder al por qué de la tardía aparición de esta disciplina en el país. La explicación que hemos ido construyendo es de carácter histórico, plantea que los intelectuales chilenos, de carácter proestatista, trataron de observar y proponer -privilegiada y voluntariosamente- la homogeneidad de la población chilena, que sería la "supuesta" base de la fortaleza del Estado. Los extranjeros en cambio, muchos de ellos de visita en Chile, sin el prejuicio de la homogeneidad de los chilenos, sin esa entusiasta e ideológica concepción unitarista, vieron las enormes diferencias internas de la población y fueron quienes iniciaron los estudios propiamente antropológicos en nuestro país. Siguiendo esta tesis crítica, se observa el carácter profundamente folklorizante y conservador que ha tenido la antropología en nuestro país y se aboga por una antropología crítica.

El artículo comienza con los precursores de la antropología, cronistas españoles que observaron por primera vez, desde un punto de vista religioso o militar, la situación de los indígenas y son una fuente indispensable para su comprensión. La "crítica de fuentes" es indispensable y central en esta parte de la historia. Seguimos con los "viajeros", que en el siglo XIX y comienzos del siglo XX, vinieron a Chile y nos brindaron descripciones fenomenales de esta sociedad. En particular de su diversidad. Esos "sabios", por lo general "naturalistas" que recorrían el mundo, pasaban raudos por Santiago y se entrometían en todos aquellos rincones que los chilenos despreciaban y no veían o, en muchos casos, no querían ver.

Creemos que la antropología en Chile tiene un hito importante en la publicación, a fines del siglo XIX, del libro de don José Toribio Medina, Los aborígenes de Chile. Es el mayor compendio de la época, que resume no solo todo lo que se conocía de los testimonios anteriores, sino también las teorías más modernas de la antropología mundial. Con alguna osadía, uno podría decir que con ese libro se inaugura la antropología en el país. Medina clasifica, ordena, reúne valiosos testimonios orales, conoce a los cronistas y viajeros como nadie. Marca, sella y, quizás, condena con su obra la concepción de las elites chilenas acerca de los indígenas de este país, utilizando las categorías "morguianas" de salvaje, bárbaro y civilizado, en fin, el menosprecio de las sociedades prehispánicas existentes y el aprecio por algunas de sus manifestaciones materiales (Medina, 1882).

Por este motivo, en este artículo se analiza en detalle el evolucionismo de fines del siglo XIX, ya que consideramos que es la doctrina antropológica corriente en nuestro país. El evolucionismo caló muy hondo en la conciencia general de las élites y de las "personas cultas" de esta sociedad. Vino a santificar "científicamente" los estereotipos. Barros Arana, en el primer tomo de su Historia General de Chile, extraordinaria obra historiográfica que estableció el corpus de la "Historia Oficial" nacional, pone a los indígenas en el primer estadio de la evolución y se refiere a veces con dureza a sus condiciones de vida. Con casi ciento treinta años de escrito dicho libro, se lo sigue leyendo acríticamente en "variadas variaciones" escolares y en no pocas denominadas "científicas". 
La antropología nace evolucionista y tendrá en ese sello de bautismo su pecado original. Todo aquel que quiera estudiar temas antropológicos, al menos en Chile, deberá asumir críticamente este hecho y mostrarse despiadado contra la noción corriente que sobre cada uno de estos temas tiene la población, la prensa e incluso los sectores ilustrados.

El 7 de octubre de 1907, se reunían en los salones de la Biblioteca Nacional un selecto grupo de personas, autoclasificadas como "sabios", que darían lugar más adelante a la Sociedad Chilena de Historia y Geografía. Podríamos decir que aquí se funda el espacio significativo o, como diría Michel de Certau, "espacio de producción", en que comienza propiamente la antropología en Chile $^{2}$. Era una copia de las "Sociedades Científicas" que en Europa y Estados Unidos habían tenido tantos éxitos y famas. Este origen marcará a fuego la antropología chilena: señores, normalmente ricos y "cultos", que se reunían para analizar este tipo de temas sin intereses pecuniarios de ninguna naturaleza, muchos de ellos coleccionistas, filántropos. Pertenecer a esa Sociedad era un asunto de prestigio.

Hemos denominado a este período como "Rescatismo". Los rescatistas de la Revista Chilena de Historia y Geografía, una de las publicaciones más importantes en la historia de la antropología chilena, van a considerar que su acción es de tipo "misionera", esto es, rescatar los fragmentos de las culturas condenadas a desaparecer. Gusinde, Latcham, Lenz, Guevara, y tantos otros, son los personajes que inundan este período. No cabe duda de su importancia gigantesca. Muchos frailes capuchinos alemanes van a confeccionar diccionarios, gramáticas, recopilar historias, memorias, fragmentos de las culturas prehispánicas de Chile.
Sin la enorme producción rescatista de los inicios del siglo XX, careceríamos de conocimientos de esas culturas ${ }^{3}$.

Luego, hay un período de transición en que comienzan a llegar influencias de diversas corrientes antropológicas del mundo y en el país no se establece aún una institucionalidad que las acoja productivamente. Es así que las ideas del indigenismo mexicano llegan a Chile por intermedio de la brillante voz de don Alejandro Lipschutz. Las teorías de la antropología norteamericana, por su parte, lo hacen en la certera pluma de Louis Faron. La antropología francesa se hace presente con Alfred Metraux y Joseph Emperaire, y así muchos otros. Es un momento intermedio entre los antiguos precursores rescatistas y la "antropología académica".

La no existencia de un espacio académico para la antropología, condujo a que muchos temas que hoy en día serían propiamente antropológicos, fueran desarrollados por disciplinas fronterizas; es así que en el Instituto de Geografía de la Universidad de Chile, se instalarán los estudios campesinos. Cómo no recordar con cariño y pasión las obras de Rafael Baraona, tanto geógrafo como etnólogo: el Valle de Putaendo es de las mejores etnografías sobre el campo tradicional chileno.

Será recién a mediados de la década de los sesenta que la antropología logrará ingresar a la Universidad de Concepción y, a fines de esa década, a la Universidad de Chile. Consideramos que es una nueva etapa y la denominamos como la "antropología académica". Con el paso de los años la valoramos cada vez más. La figura de Don Carlos Munizaga Aguirre crece con el tiempo. Hasta ese momento la antropología tenía en los temas indígenas su único "objeto de estudio". Munizaga "viaja con los migrantes mapuches" 
a la capital y, en ese mismo acto, traslada la antropología desde el campo a la ciudad. Sus estudios de migración lo conducen a la Quinta Normal, a la calle Matucana, donde se reunían los indígenas que venían del sur. Son los mismos que lo "llevan" también al Hospital Psiquiátrico introduciendo a la antropología en los estudios transculturales y en la psiquiatría transcultural. Otros destacados maestros de esa generación son: Alberto Medina, Francisco Reyes Catalán, Carlos y Juan Munizaga, este último fundador de la Antropología Física, María Ester Grebe, Mario Orellana y muchos otros que comenzaron estas actividades académicas. En esos años surgen además otras escuelas de antropología y recién en los setenta, después del golpe de Estado, se titulan los primeros antropólogos profesionales. La Escuela de Antropología de la Universidad de Chile sobrevivirá al cierre de las escuelas de Sociología, Ciencias Políticas, la Facultad de Economía Política, en fin, a la erradicación de las ciencias sociales durante casi dos décadas por ser consideradas subversivas. Como puede comprenderse, la antropología, por su origen y trayectoria, no representaba el mismo nivel de criticidad y amenaza y se mantuvo impertérrita funcionando. Habrá que explicar este fenómeno. En el sur, en el cambio, la Escuela de Antropología de la Universidad de Concepción fue cerrada inmediatamente después del golpe de Estado, expresando de manera clara el compromiso intelectual crítico al que adhería. Allí, un grupo de antropólogos argentinos y chilenos, harán un aporte enorme a la diversificación teórica de las temáticas antropológicas. Más al sur, en la Universidad Católica de Temuco, seguimos la pista a la obra de Milan Stuchlik, quien había llegado desde lo que entonces era Checoeslovaquia y se había involucrado de manera profunda en las comunidades mapuches cercanas a Temuco y Chol Chol. Como tantos otros, en 1973 debió salir del país. La Universidad de Cambridge fue su destino. En busca del peligro y aventura constante, se trasladó a Ulster, donde en la Universidad de Belfast, escribió, publicó y falleció en 1980. Las alumnas de la Escuela de Antropología que él formara, Fresia Salinas, Cecilia Dockendorf, junto a Teresa Gottlieb, tradujeron y publicaron La vida en mediería (1999) 4 . Esas escuelas fueron cerradas después del golpe de Estado, expresando de ese modo que allí se fraguaban los inicios de lo que denominamos la "antropología crítica".

A partir de los años ochenta la antropología comienza a buscar nuevos derroteros y se desliga de la cuestión indígena como único tema de estudio. Sigue manteniendo su importancia el tema étnico, pero surgen numerosas otras subdisciplinas. El primer Congreso de Antropología, y no es fe de erratas, se realiza en Santiago de Chile en 1985, en plena dictadura. No es casualidad que se realice en la sede de la Comisión Chilena de Derechos Humanos y no en la Universidad de Chile. Este local quedaba en la Alameda en los altos del afamado y, hasta hoy conocido, Café Torres; ahí, por primera vez aparece la enorme diversidad de temas que ya abordaba la antropología y que comprometía a los antropólogos, muchos de ellos trabajando en ONG, acompañando movimientos sociales, procesos de resistencia a la dictadura, desarrollando planes culturales en poblaciones, haciendo documentales e incluso cine. Ya no era la mirada ni rescatista, ni academicista de períodos anteriores. El "punto de vista", siguiendo nuevamente a De Certau, había cambiado, esta vez, por la fuerza.

En la década de los noventa, con la denominada "Transición a la democracia", comienzan a surgir nuevas escuelas de antropología. 
Tímidamente en un comienzo y, cada vez con mayor vigor, se profesionaliza la actividad. Por primera vez son requeridos antropólogos en servicios públicos, consultoras, e incluso en empresas privadas. La temática del patrimonio nacional, del patrimonio material e inmaterial también produce una demanda de especialistas y, finalmente, los "Estudios de Impacto Ambiental" exigen la presencia de arqueólogos y antropólogos en proyectos de enorme envergadura.

Desde sus orígenes oligárquicos, de la "hora del té" en los salones de la Biblioteca Nacional, hasta el duro, controvertido y bien remunerado trabajo de las consultoras, convenciendo a poblaciones a que se trasladen porque se construirá una central hidroeléctrica, o una carretera, han pasado muchos años y más de un cambio epistémico. La antropología en Chile aún está en barbecho y no se ha consolidado. En este artículo se analizan los aportes, los caminos que se abren, y se critica fuertemente el carácter conservador de muchos de los que se dedicaron y dedican a esta profesión. No ha sido menor el hecho que los antropólogos se han visto involucrados en situaciones profesionales complicadas, justificando situaciones que van en contra de poblaciones y pueblos indígenas o que, mediante el conocimiento de metodologías y teorías sobre el comportamiento humano, apoyan sistemas de manipulación. La profesión de la antropología está en entredicho, tanto en su pasado en que se unió de manera poco crítica a los procesos denominados de "civilización", que en la mayoría de los casos fueron de colonización, cuando no de exterminio, como ahora, cuando muchos antropólogos o personas que han estudiado esa carrera, o que simplementemente ostentan un cartón con ese título, son los acompañantes de procesos denominados de "modernización", que no son menos devastadores que los de la primera oleada de colonización del siglo XIX. Antes, los antropólogos, como la famosa imagen de Malinowski en las islas Trobriand, se vestían de blanco, botas altas y "cucalón" en la cabeza, hoy andan con sus computadoras, teléfonos satelitales y mochilas cargadas de "proyectos de desarrollo". Difícil desafío para estas disciplinas tan ligadas a las hermosuras y miserias del ser humano.

El curso dictado en la Academia de Humanismo Cristiano normalmente concluye en estos tiempos modernos y pantanosos de la antropología, con una reflexión sobre la "responsabilidad del antropólogo" o, lo que es lo mismo, sobre "Ética y Antropología". Este artículo, demasiado largo, se queda en tiempos más antiguos, por prudencia y, quizá, perplejidad.

\section{Unidad y diversidad}

El Estado, tanto en Chile como en cualquier otro lugar del mundo, ha sido y sigue siendo una "voluntad de unidad", en medio de una sociedad que no tiene demasiadas raíces comunes que la unan o que, junto a ellas, tiene numerosos aspectos que la separan. El Estado siempre es un proyecto inacabado de unificación. Un conjunto de símbolos, rituales, leyes, normativas, tradiciones, burocracias, sistemas de enseñanza, aprendizaje, creencias y autoridad. El Estado es un discurso acerca de un "nosotros", de una sociedad en permanente construcción. Siempre está el peligro de la disrupción, de la ruptura de las partes que conforman ese Estado. Es por ello que el Estado es autoridad y sus aparatos y sistemas burocráticos tienen por función reproducirlo, defenderlo y reprimir cualquier manifestación de carácter centrífugo que debilite su unidad. Estas aseveraciones que son ciertas para la generalidad de los Estados, son 
más fuertes, sin duda, para los Estados jóvenes, donde las tradiciones son menos profundas y donde los sistemas de autoridad son muchas veces fáciles de subvertir.

Chile, como cualquier país moderno, está constituido por una diversidad de grupos humanos. Cada uno de ellos forma parte de la sociedad chilena y le otorga un valor especial. Indígenas, campesinos, trabajadores, grupos migrantes, pobladores de barrios, jóvenes de las esquinas, pescadores, arrieros de las montañas, descendientes de colonos extranjeros, profesores y empleados, la clase o las clases de los políticos, mineros, gente del desierto, militares y gente reunida en agrupaciones, sociedades de la más diversa estructura y finalidad. Muchas veces el país y su historia se comprenden desde la estructura política estatal, que por su naturaleza y definición es unitaria, homogénea y expresa la idea de un país único y unido. La antropología por el contrario, desde sus inicios, ha tratado de comprender lo específico de cada grupo humano existente al interior de las sociedades mayores. La trayectoria de la Antropología en Chile es un largo proceso intelectual en el que numerosos intelectuales y observadores han ido mostrando la diversidad interna de la sociedad chilena.

\section{Antropología e Historia}

Las Historias oficiales han sido y son por lo general "Historias del Estado" y, por tanto, intentos más o menos exitosos de entender a las sociedades de acuerdo a la lógica de la homogeneidad, de la unidad e integración social. Se busca el origen común de los habitantes, los mitos colectivos que los identifican, las epopeyas que los ennoblecen, las diversas batallas e historias épicas que los hacen orgullosos de vivir en común ${ }^{5}$.
Las diversidades se esconden como pequeñeces, no necesariamente "relatables", de la historia colectiva, a veces, incluso, con vergüenza. El Estado, sus próceres, funcionarios, héroes y estadistas son quienes "hacen la Historia". La gente común, con sus intereses particulares "y mezquinos", queda relegada a los márgenes.

La "Historia" tiene por función entre otras cosas, (aunque quizá es la más importante), construir los "lazos primordiales" de la sociedad; cuando esos lazos no han surgido necesariamente en forma espontánea en "tiempos primordiales" y son herencia de "nuestros ancestros"6. Tradicionalmente ha sido la escuela y la "enseñanza pública", el instrumento de homogeneización cultural, de trasmisión de los símbolos patrios y comunes a todos los ciudadanos.

La mayor parte de las ciencias sociales, ha seguido este derrotero ideológico. La mirada unitarista, integracionista y estatista, ha conducido a valorar ciertos aspectos de la vida social y, a desvalorizar otros. La Historia ha sido en buena medida "la" ciencia social de mayor respeto, justamente por su carácter proestatal. En nuestro país, en particular, la denominada "Historia de Chile", surge como un intento positivo y racional de otorgar al Estado un "discurso civilizador". Desde las primeras "historias", hasta las "megahistorias de Chile", de Barros Arana y Encina, principalmente, el objetivo es "construir" la nacionalidad. Porque la Nación, es el sustento del Estado. Para que exista un Estado fuerte, se ha dicho muchas veces, debe haber patriotismo en sus habitantes, debe existir un fuerte concepto de pertenencia.

Los discursos nacionales y nacionalistas son o, han sido casi siempre, discursos estatalistas, intentos de dar unidad a la diversidad, coherencia a las incoherencias 
de la historia, sentido a las contradicciones. Los discursos más virulentos, son generalmente aquellos que se construyen cuando no existe un Estado que represente los intereses expresados o deseados. El nacionalismo italiano y alemán, por ejemplo, fueron resultado de la sensación de incapacidad de sobrepasar las comunidades locales o regionales con sus especificidades y organizar el "ecumene" común. Los orígenes del racismo alemán, en particular, se remontan a esa dificultad de encontrar "lazos primordiales", que en vez de aunar voluntades, expulsaron a los que no se autorrepresentaban en ese proyecto. Quizás, todos los racismos están ligados a esta deficiencia en el desarrollo del Estado como ente racional de unidad e integración.

En Chile se suele señalar que el discurso nacionalista y racial es débil. Probablemente se deba a que no es preciso la existencia de discursos altamente constructivistas, ya que existe un nacionalismo autoaprendido y "bebido desde la cuna", sobre el cual no hay dudas en la población. Es así, que en el período que más se desvalorizaba a los trabajadores en el ámbito económico, peones e inquilinos de las haciendas de mediados del siglo XIX, el Estado levanta al nivel de mito fundacional de la nacionalidad al "roto chileno", otorgándole un valor simbólico a la nobleza del "bajo pueblo". El "roto" se va a transformar desde el inicio de la república en el alma nacional y sus hazañas en las guerras nacional-estatalistas, serán la base de un discurso de integración que recubrirá las explotaciones y miserias, con el "suave manto" de la unidad nacional. Desde la batalla de Yungay, cantada y relatada en todas las generaciones escolares desde mitad del siglo XIX, hasta la "subida" del Morro de Arica a fines de ese siglo, los "lazos primordiales" que unen a los chilenos se fundamentan en la sangre de "sus rotos", capaces de dar la vida por la patria. Ese fundamento heroico, interclasista, ha posibilitado la creencia de una homogeneidad ancestral en la población del país $y$, frente a la cual, el Estado se ha fortalecido ${ }^{7}$.

\section{Antropología y megarelatos}

En ese contexto, y esta es la materia de nuestro trabajo, las disciplinas que recurrían a explicaciones diversificadas del fenómeno social, como la antropología, o no tenían cabida en el discurso dominante $o$, estaban relegadas a la marginalidad, al "folclore" o a los museos.

La antropología, desde esta perspectiva, trataba de asuntos marginales que no se ubicaban en el centro de las preocupaciones de un tiempo de crisis y cambios estructurales. Más de una vez, los problemas de las culturas tradicionales se analizaron como "factores que dificultan el cambio social". Tomás Borge, Comandante de la Revolución Nicaraguense, no demasiados años atrás, al analizar los problemas suscitados en la Costa Atlántica con los pueblos Misquitos, dijo sin rubor: "nosotros éramos revolucionarios y no antropólogos".

No es por casualidad que quienes se dedicaron a la antropología en esos años turbulentos de América Latina y Chile en particular, optaron, con muy pocas excepciones, por tendencias políticas conservadoras. Su mirada era entendida como una observación de los márgenes de la historia que, en esos días, se estaba construyendo en forma ardiente e inminente. La trayectoria de la antropología en Chile no puede olvidar estos contextos, sin los cuales no se comprende la debilidad disciplinaria, la tardanza en constituirse la cuestión étnica y los temas de la diversidad en Chile. 
La crisis de esos "megarelatos" ha puesto una vez más en vigencia estas miradas disciplinarias, de mayor complejidad y menor voluntarismo. La relatividad de la mirada antropológica, y el pesimismo subyacente a cualquier observación psicologista del ser humano (su pequeñez frente a sus desafíos según Freud), han conducido a partir de finales del siglo $X X$ a revalorizar lo que con anterioridad era asumido como esencialmente de poca importancia. La crisis profunda de los paradigmas macrohistóricos, su incapacidad de comprensión, ha dirigido las miradas a sistemas no cerrados, tampoco con la pretensión de transformarse en modelos de comportamiento general. La casuística relativista de la antropología ha sido un fenómeno de la mayor importancia, frente a la incomprensión que las llamadas ciencias duras han tenido de los fenómenos sociales.

La historia con "hache mayúscula", por ejemplo, la historia oficial estatalista, ha sido soterrada por las miradas antropologicistas, o que se plantean una mirada más bien incrédula frente a la heroicidad sin parangón de ciertos seres humanos sometidos a la presión del amor a la patria, o a la visión magnífica de las clases sociales luchando en contra de las injusticias y bregando en función del paraíso. La desconfianza de la psicología, y las crecientes interrelaciones entre cultura y personalidad, tema común de psicólogos y antropólogos, ha conducido a mirar con desconfianza las "semblanzas" de los líderes en las que sus virtudes personales (y su exacerbada fiereza de voluntad y sentido de la Historia), explicaban los procesos y hechos de su tiempo ${ }^{8}$.

La antropología, al contrario de las otras ciencias sociales, permitiría una mirada de la diversidad del país, de sus diferentes culturas, de la amalgama enorme de variedades de lo que es "ser chileno". A lo largo de la historia, numerosas personas han observado esas particularidades, las han escrito, dibujado, relatado. Ese conjunto de conocimientos sobre nuestra diversidad constituye, a nuestro modo de entender, la base de comprensión de la trayectoria de la antropología en Chile.

\section{Los primeros observadores}

En Chile, los primeros que observaron la diversidad de la realidad fueron los viajeros. Venían de otras culturas y les llamaba la atención lo que veían. En particular les llamaba la atención la cultura popular, las culturas indígenas, los elementos autóctonos. Las clases altas, eran poco interesantes para ellos. Las clases altas refinadas y afrancesadas del siglo XIX en América Latina, eran motivo o, de incrédula sonrisa o de sorna callada, por parte de los viajeros. En cambio, el tema de interés estaba en la gente que habitaba a la usanza local, particularmente en los indígenas. Muchas veces esas costumbres eran despreciadas por las clases altas y, no pocas veces, no entendían el por qué de ese interés por "gente despreciable" y de costumbre bárbaras. No es casualidad, por lo tanto, que en la mayor parte de los casos la antropología surgiera de viajeros $y$, sobre todo, de viajeros extranjeros. El viaje abre la mente a lo desconocido, a lo insólito, a lo inesperado. El viajero por tanto está más abierto a la diferencia. Si bien es cierto que la antropología es una disciplina tardía en Chile, esto no significa que no hayan existido muchos observadores perpicaces de la realidad cultural chilena. Lo que une a estos observadores con la antropología, evidentemente no es el método, sino el punto de vista. 
Por diversas "razones, estas personas tuvieron un interés en conocer lo que pensaban, hacían, y cómo vivían los otros" que habitaban Chile. Sus observaciones son de la mayor importancia para el conocimiento antropológico del país. Sin ellos la "antropología" no tendría historia.

\section{Cronistas "etnólogos"}

Los conquistadores españoles desarrollaron un estilo literario denominado crónica, muy apreciado en la península y que se desarrolló enormemente en los años en que se produjo la conquista americana. Este estilo tenía una cierta reglamentación y su utilidad era obvia: informar al rey de lo que iba sucediendo en la conquista de los nuevos territorios, ya que en general iban dirigidas a él. Quizás, lo que más caracteriza a la crónica es su estilo redactado en primera persona. El cronista es el testigo. Esto es importante tenerlo en cuenta, pues, si bien es cierto, en muchos casos el cronista es realmente testigo de lo que vio y participó, en muchos otros casos no lo es, sino que escuchó la historia, la leyó de otro manuscrito o simplemente la reconstruyó con base en fuentes no identificadas.

Las crónicas corresponden al período temprano de la conquista y, en Chile, acompañan buena parte de la Guerra de Arauco, ya que a pesar de los años pasados aún existían "hazañas" que contar. Las crónicas las ubicamos en los siglos XVI-XVII, ya que después se va cambiando hacia la utilización del género histórico general, de carácter más modernista, renacentista incluso, como son las Historias que publican los jesuitas en el siglo XVII y sobre todo XVIII. Ese estilo pretende seguir las leyes de la historiografía y se plantea asuntos más complejos, como por ejemplo la descripción detallada de la geografía, del clima, de las personas que viven en el lugar, sus costumbres y características ${ }^{9}$. La historia, o historias, desarrollada desde el siglo XVII en adelante, nos dan información de mucha calidad sobre lo que ocurría con los indígenas durante el período colonial. Hay que tener en cuenta, por cierto, y de modo crítico, el hecho que muchos "historiadores" copiaban manuscritos anteriores sin citarlos e, incluso, cambiándolos a su entero antojo. No existía la formalidad propia de fines del siglo XIX, de "citar" a los autores a los que el historiador se refería, no existía la idea de fuente. Algunas de esas historias generales sobre Chile tienen una evidente importancia, como la que el jesuita Ignacio Molina, conocido como el Abate Molina, publicara en Europa después de ser expulsado del país junto a los hermanos de su orden a mediados del siglo XVIII. Para la antropología, y en especial para los estudios sobre asuntos indígenas, estas son fuentes indispensables.

Por cierto, hay otros estilos literarios. Las Cartas de Relación, en que el capitán adelantado le escribe al monarca lo que está haciendo y cuáles son sus planes, es uno de los estilos comunes de la época. A diferencia de la crónica, la carta va dirigida a la persona del rey en todas sus partes, por lo que no es un relato de un escritor más bien anónimo que observa y describe los hechos en los que le ha tocado participar. El lector de las Cartas de Relación, debe tener siempre en consideración los intereses determinados y específicos que tenía el "adelantado" al escribirle al rey. Por lo general estos intereses estaban dirigidos a apropiarse de lo realizado en la conquista, de obtener beneficios, de solicitar mas hombres y armas, apoyo especial de la Corona. 
Es por ello que, a veces, como es el caso de Valdivia, pinta la realidad del país con colores más bien brillantes, a pesar de que los hechos en los que estaba involucrado eran tan complicados que lo llevaron a la muerte. Es preciso, entre los muchos cuidados que hay que tener al analizar y trabajar estas fuentes, prevenir que el escritor no siempre es el mismo Capitán. Muchas veces ese capitán ni siquiera era letrado. Para ello tenía un escribano que lo acompañaba y le servía para esos propósitos.

Vivar (o Bibar), ha sido uno de los mayores observadores de "los indios de Chile", como él los denominó. En su crónica, Vivar recorre valle tras valle, contándonos las creencias y costumbres de los indígenas de Chile. En algunos casos, al parecer, fue testigo presencial de los hechos y, en otros, refirió en primera persona lo relatado por soldados y otros testigos.

El análisis crítico de Vivar nos conduce al conocimiento que los soldados españoles tenían de los indígenas y sus costumbres, no directamente a las costumbres de los indígenas. Es una distinción fundamental para el buen uso etnográfico de estos textos. Nada sabemos de lo que pensaban, hacían, de cómo vivían y trabajaban los indígenas de Chile al llegar los españoles. Sabemos lo que los españoles pensaron acerca de esos asuntos. No es poco. Pero es necesario hacer la diferencia. La haremos al analizar cada uno de los casos aquí escogidos. Si no se ejercitase esta necesaria argumentación crítica, se puede llegar a abusos absolutamente impropios en la utilización etnográfica de las crónicas españolas en América. En cambio, un análisis cuidadoso y crítico de esos textos, puede entregar grandes conocimientos acerca de cómo estaba organizada la sociedad prehispánica.
La descripción etnográfica de Vivar es de gran calidad. Quizás su observación acerca de la lengua de los indígenas sea la aproximación más importante y útil. Vivar va diciendo a lo largo de su tránsito por los diferentes valles y localidades del sur del país, quiénes son de la lengua del Mapocho donde se construyó la capital del Reino, Santiago de Chile o Santiago del Nuevo Extremo, con lo que nos muestra que, lingüísticamente, los indígenes chilenos hablaban un mismo idioma, desde a lo menos el Mapocho hasta el seno de Reloncaví. Esta unidad lingüística de los indígenas resalta con la diferenciación étnica que se puede percibir a través de las mismas descripciones. Unidad y diversidad están trabajados por Vivar de una manera brillante y moderna para los criterios que hoy maneja la etnografía. Es por esa capacidad de describir, a veces con cariño y aprecio a los indígenas de Chile, que podemos decir que por esa pluma, habría comenzado la etnografía chilena.

\section{Soldados y Cautivos: la observación participante}

Pineda y Bascuñán es el primer testigo directo de la vida cotidiana mapuche, lo que hoy día en antropología se podría denominar, un "observador participante".

En Chile, a diferencia de México y Perú, no hubo "cronistas indígenas", es por ello que el texto de Pineda y Bascuñán, El Cautiverio Feliz, es lo mas cercano a una visión directa del indígena. Barros Arana, el famoso historiador chileno del siglo XIX, que tenía una pobre y mala opinión de los indígenas chilenos, se encargó de desprestigiar esta crónica. Señaló, muchas veces, que Pineda y Bascuñán se dejó llevar por una visión religioso-romántica. Ciertamente, Pineda y Bascuñán hace una crítica 
a la política de la Corona y, para ello, se basa en textos religiosos que le permiten apoyar con argumentos de autoridad su posición que sin duda, no es fácil de sostener por un español de la época.La lectura de El Cautiverio Feliz, es muy difícil. Si se siguiera a la letra lo que describe el autor, la imagen de los indígenas del sur de Chile sería totalmente diferente a la que nos han entregado los historiadores positivistas. Grandes construcciones, una sociedad de la abundancia, a pesar de la guerra, en fin, muy diferente a la pintura primitiva dibujada por la pluma evolucionista tributaria del concepto de "barbarie". Es por ello que este libro ha sido o poco conocido, criticado o ridiculizado ${ }^{10}$.

El valor de las crónicas en la antropología está dado por ser los primeros caudales de información etnográfica utilizada en la investigación, aportándonos en la discusión teórica con tempranos cuestionamientos sobre la realidad observada. Otro ejemplo de este tipo de análisis temprano, es el realizado por otro cronista de la colonia española, conocido como Alonso González de Nájera.

Nájera es un hombre culto del renacimiento europeo. Viene de maestre de campo del famoso Alonso de Rivera, Gobernador de Chile enviado a poner orden en el Reyno después del llamado "Desastre de Curalava" y la destrucción de las ciudades del sur. Nájera nos sorprende con sus preguntas pertinentes. Se pregunta permanentemente sobre "¿cuál será la fuerza de estos indios?" Vemos en sus preguntas una idea central de la antropología. El soldado, con larga experiencia en Italia, trata de comprender a "su enemigo" y, para ello, describe de modo extraordinario la vida, rituales, costumbres, en fin, a la sociedad que tiene en frente.
La verdad de estos relatos es irrebatible: si se equivocaba se le iba la vida en ello ${ }^{11}$.

\section{Los jesuitas: etnografía y misión}

En el origen de la antropología como oficio, en todas partes del mundo, están los misioneros. Las necesidades de la evangelización condujeron, donde hubo movimientos colonizadores y evangelizadores, a tratar de entender el idioma local, las costumbres y otras características de los seres humanos a quienes se "perseguía" convertir. Los mejores testimonios de culturas están hechos o por militares, o por misioneros. Es preciso no olvidar que el clero y en particular los frailes de congregaciones religiosas, conformaban la elite intelectual de la época, por lo que es casi obvio que ellos fueron los que mejores descripciones nos dejaron de lo que veían en el Nuevo Mundo. En Chile no fue novedad. Los jesuitas jugaron un papel central en las misiones entre los mapuche a partir del inicio del siglo XVII y nos han dejado los mejores testimonios sobre sus costumbres. El Padre Luis de Valdivia es la figura central en el inicio de la reflexión jesuita sobre los "indios de Chile". Valdivia es un lingüista por necesidad. Escribe la primera gramática de la lengua indígena que, como se ha dicho muchas veces, nos deja lo que era el habla de los indígenas de la región del Bio Bio, tanto hacia el norte como hacia el sur, donde vivió y misionó el Padre Luis de Valdivia. Su objetivo era construir una sociedad indígena cristiana, al igual que lo que pretendieron hacer sus colegas en el Paraguay con los indígenas guaraníes. Logra durante algunos años su sueño en Catiray, un lugar hoy en día inexistente, del que tenemos pocos datos y que estaría ubicado en la Cordillera de Nahuelbuta al sur del río Bio $\mathrm{Bio}^{12}$. 
En Catiray, el Padre Luis logró construir la paz, iniciar un proceso de sedentarización, enseñanza de la agricultura y separación de los indígenas de los soldados y encomenderos. La función de los jesuitas era la "protección del indio", de modo de separarlo de los peligros de la colonización brutal y acercarlos a través del respeto a las creencias religiosas del cristianismo.

\section{Viajeros}

La antropología moderna, nos podríamos preguntar, ¿ha surgido de los viajeros? Es cierto que primeramente fueron los cronistas y los misioneros los principales observadores de las culturas no europeas. Con el tiempo, la función de la observación se fue privatizando y secularizando. El descubrimiento de sociedades no occidentales, denominadas "primitivas" por los europeos, fue creando la necesidad de comprender tales sociedades, motivando a diferentes individuos la inquietud por viajar. Lo que sí podemos decir, es que la antropología tiene una estrecha relación con los viajeros, sin dejar de considerar también a los misioneros como lo hemos dicho más atrás. Pero estos se distinguen entre sí, porque las motivaciones para los misioneros eran religiosas $y$, para los viajeros, eran lo que en ese tiempo se entendía como "científicas".

En el siglo XIX, la antropología se cultiva con las preguntas y relatos que desarrollan los viajeros. Los viajes prototípicos van a ser dos, el de Humboldt a fines del siglo XVIII, quien va a dar a conocer las colonias españolas al mundo europeo no hispánico y el de Darwin, a mitad del siglo XIX. Su libro no solo conmocionó el mundo intelectual por sus observaciones en torno a la evolución, sino que llenó el imaginario de cientos de personas, ricas por lo general, que vieron en el "viaje" el sentido de sus vidas. El siglo XIX, podríamos afirmar, es el siglo de los viajeros. Se trataba de una empresa de largo aliento que tenía por objeto aprender nuevas experiencias, nuevos conocimientos y llevar al viejo mundo relatos de las aventuras pasadas. El "viaje" es un asunto culto, planificado, que por lo general culmina al regreso con una exposición detallada, frente a un auditorio expectante de conocer las aventuras y hallazgos. Los museos europeos están repletos de artefactos sustraidos por esos viajeros ávidos de recopilar materiales de otras culturas, guardarlos como trofeos de la capacidad cognoscitiva de occidente. Los viajeros trataron de conocer el mundo y apropiarse de toda su cultura.

El "viajero", se transforma en una profesión o actividad valorada en sí misma. Está dominado por una pasión aprobada socialmente. Se crean asociaciones de geografía, de naturalistas, de historia natural, de todo tipo, que serán la base del desarrollo de las primeras grandes teorías antropológicas, geográficas e incluso de historia universal.

El aporte de estos escritos en la antropología es obvio. Al no estar ligados a los intereses directos de la nación colonizadora y no rendirle servicios directos a sus agentes de colonización, por lo menos en el caso de los ingleses, franceses y alemanes en Chile, sus observaciones aparecen con una mirada no tan directamente comprometida. Es una mirada curiosa, circunscrita a lo que en ese momento se consideraba "lo culto" y ligada al despertar del nuevo impulso de globalización mundial que se produce con las independencias americanas.

Estos escritos surgen de una situación totalmente distinta a los registros de los primeros españoles, 
que eran políticos/funcionarios de la Corona, militares o misioneros. Los viajeros, al no interesarles ni las guerras, ni las misiones, no se sienten involucrados en los problemas que acontecían en el país y, en sus escritos, relatan los hechos que observan sin tantos intereses inmediatos o ligados a las tareas de la conquista o las misiones. Se entrometen de ese modo en la vida cotidiana, en las condiciones económicas y, con un pensamiento por lo general liberal y abierto, tienen la posibilidad de acercarse desde otros "puntos de vista" a esas realidades. Sus únicos intereses (que no son pocos), tienen que ver a menudo, con las aperturas de nuevos mercados y de informar lo que ocurre con las riquezas.

De los relatos de los cronistas a los relatos de los viajeros hubo un quiebre en los intereses y en el punto de vista que se plasma en el contenido de lo escrito. Los cronistas tienen relatos históricos y los del siglo XVIII, especialmente en Chile, están casi todos marcados por la manera de contar la historia de esos años. Su objetivo es lograr demostrar la larga presencia del mundo "hispano católico" en América y los atributos que ese hecho implicaba. En cambio, los viajeros se preocupan más bien de la geografía, de la naturaleza, y hacen poca referencia a la historia.

A fines del siglo XIX las sociedades geográficas europeas o norteamericanas organizaron diversas expediciones profesionales. Con la expansión europea de aquellos años se produjo una explosión de tales expediciones. En dichos viajes, las sociedades científicas, junto con el examen de los nuevos territorios, también incursionaron sobre grupos humanos distintos, tarea que desempeñó fundamentalmente la geografía humana, cuestión que también puede ser considerada como el primer brote del conocimiento antropológico.
En general, en el siglo XIX hay una desesperación por conocer el mundo y esa obsesión también llega a Chile. En Chile, son muchos los viajeros que llegan por diversos motivos y que nos han dejado excelentes descripciones del país. Podemos mencionar, brevemente, a Poeppig, alemán que llega durante los primeros años de la independencia y que viaja por diversas partes del país. Se interna en territorio Pehuenche, recorriendo el camino más importante de los indígenas chilenos y argentinos para cruzar con animales y productos de uno a otro lado. Sus descripciones de los dias que ahí estuvo, son muy útiles como fuentes para comprender cómo era la sociedad pehuenche de ese tiempo. Otro viajero, es el estadounidense E. Reuel Smith, quien se introduce en la Araucanía desde Chillán con un guía y lenguaraz. Su descripción de la gente que encuentra es extremadamente rica. Sobre todo su conversación con el famoso Cacique Mangin o Mañil Wueno, que por ese tiempo era el principal jefe de los mapuches llamados "arribanos", de los que vivían en las inmediaciones o faldeos de la cordillera de los Andes. Habla con Mañil y nos entrega un testimonio directo de esa conversación. Un caso de viajero diferente al anterior es Paul Treutler, quien llega a mediados del siglo XIX en busca de oro. Parte desde la ciudad de Valdivia con caballos y mulas, internándose en el territorio indígena del sur de Chile. Es recibido en la casa de uno de los grandes caciques del sur y describe la vida cotidiana de los indígenas en ese tiempo. Sus observaciones son muy ricas para comprender lo que era la Araucanía en la década del cincuenta del siglo XIX, justo en los momentos en que Chile se iba a enfrentar en la guerra naval contra España; la escena en que llegan los "Pehuenches" a casa del Lonko o Cacique Paillalef en Pitrufquén, daría lugar para cambiar la imaginería indígena en boga. 
Un caso distinto lo constituye Mary Graham. Viajera inglesa, de alta cultura, debe quedarse en Valparaíso despues de una situación personal, lo que le permite vivir en la ciudad, luego viajar a Santiago y conocer distintas partes de Chile. Es una gran observadora de las costumbres criollas y se hace una persona muy conocida entre la oligarquía que recién ha alcanzado la independencia del país. Escribe un texto que es un clásico entre los libros de viajeros en los inicios de la independencia chilena: Diario de mi residencia en Chile ${ }^{13}$. Nos cuenta, entre otros detalles de interés para los temas que aquí desarrollamos, cómo O'Higgins habla en mapudungun con niños mapuches que están viviendo en el Palacio Presidencial de ese entonces. En esta observación curiosa se fundamenta una larga tradición imaginaria que sostiene que don Bernardo O' Higgins Riquelme era de origen mapuche. Una corriente etno patriótica, se ha construido a partir de estos retazos. En esos años era común que los oficiales del ejército de La Frontera, esto es, cercanos al río Bio Bio, trajeran niños y niñas mapuches, ya sea para el servicio o muchas veces como rehenes de las paces que se hacían a menudo. O'Higgins era de esa zona sureña y, probablemente, mantenía relaciones de vecindad con agrupaciones mapuches, conociendo algo de su idioma.

\section{La mirada evolucionista}

El evolucionismo ingresó a Chile a fines del siglo XIX en los hombros de intelectuales e historiadores liberales. Es la única teoría antropológica que se ha transformado en "sentido común". El evolucionismo ha sido criticado muchas veces, pero sigue estando vigente en la mentalidad popular y en la cultura general de las personas.
Hoy en día consideramos cada vez más que la influencia del paso de Darwin por territorio chileno fue determinante. Su viaje en el Beagle y el contacto con los niños y grupos yagán del extremo sur de Chile ha sido y, todavía es, la observación más determinante en los estudios antropológicos, a pesar de que el viajero se autoasignaba el nombre de "naturalista". El último libro de Anne Chapman (2012) y numerosa literatura, novelada, científica y de la otra, muestran el interés e importancia de la visita del mayor sabio de la segunda mitad del siglo XIX a estas costas del Pacífico. La importancia además que ha adquirido el estudio de los ominosos "zoológicos humanos", grupos de indígenas llevados a exhibiciones en Europa, es parte del mismo síndrome.

La elite intelectual de Chile, que dominó la segunda mitad del siglo XIX, produjo un quiebre con la historiografía hispánica, constituyendo la primera generación desespañolizada, con conciencia de nacionalidad y voluntad de construirla ${ }^{14}$. A partir de entonces, la historia se comienza a construir a través de paradigmas duros respecto al pasado indígena.

El "punto de vista", cambia de manera profunda en la segunda mitad del siglo XIX. Los jesuitas, principalmente, vieron en los indígenas, y en este caso en los denominados "araucanos", una suerte de precursores del cristianismo, al mismo nivel que en la relación entre el antiguo y nuevo testamento o entre las religiones grecoromanas y el cristianismo que sobre ellas se fundó. No es fácil comprenderlo hoy, pero es necesario recordar que al ser el creador quien crea al humano (Adán y Eva) a "su imagen y semejanza", no hubo ninguna posibilidad de pensar en evolución de la especie. Los humanos desde su más anciana antigüedad, fueron tan humanos como los del presente de cada época. 
Los cronistas suelen hacer ese tipo de comparaciones, diciendo que, por ejemplo, "van a sus reuniones, cahuines, como nosotros vamos a nuestros Cabildos". Era una suerte de "prerelativismo cultural primitivo", ironizando el concepto.

Los primeros patriotas de la independencia de Chile, al igual que sus congéneres americanos, vieron en los mapuches un antecedente prehistórico de su gesta contra España. Su visión no pasó de ser romántica. La relación entre griegos y romanos estaba presente en las lógicas. Los mapuches eran la antesala de la Guerra de Independencia contra la colonización europea y eso los hermanaba.

Sin embargo, la noción de "civilización y barbarie" será el primer cambio radical en la manera de observar los asuntos étnicos. El país del centro, de Santiago y el valle central, hacendal y minero, se construye en oposición a las fronteras que lo demarcan. Mas allá, está la barbarie o el peligro de lo desconocido: el desierto y los menospreciados países indomestizos de las fronteras del norte; la frontera del sur, mundo de barbarie y bárbaros, espacio de aventuras y aventureros, campos y territorios a explorar y colonizar, naturaleza abierta a ensueños y temores por parte de los citadinos, formadores de la sociedad y el Estado nacional. El argentino Domingo Faustino Sarmiento, refugiado en Chile bajo el gobierno de Manuel Montt, será quien con mayor nitidez traiga esas nociones europeas a este territorio. Dice la anécdota, que el propio Presidente de la República (1850-1859), le habría sugerido que en vez de escribir un ensayo sobre el tema, lo novelara. De allí surgió Facundo cuyo subtítulo fue "Civilización y Barbarie" (1947). Este es un libro fundamental en la historia de las ideas. Leído religiosamente en todas las escuelas (fundadas por cierto por el propio Sarmiento), describe en este personaje mítico, la barbarie de los "interiores" de las repúblicas nacientes. Benjamin Vicuña Mackenna, uno de los intelectuales más influyente del siglo XIX, prolonga de una $\mathrm{u}$ otra forma esta visión de los "patricios" en su libro historiográfico La guerra a muerte, en él relata las guerrillas de los soldados españoles arrancados al sur del país, que se hacen acompañar en sus acciones por los mapuches. Allí se opone una vez más la civilización del centro del país, con la barbarie fronteriza del sur. A diferencia de las batallas de la independencia del sur de Chile, que fueron "civilizadas" -ya que se realizaron de acuerdo con el código estético militar napoleónico-, las batallas del sur fronterizo son bárbaras, sangrientas, crueles, "a muerte". La oposición binaria de Civilización y Barbarie iba a anunciar el evolucionismo, que por algo se autodenominó "científico".

Diego Barros Arana dibuja en su primer tomo de la Historia General de Chile la vida de los primeros habitantes de Chile con trazos oscuros, despreciativos e incluso avergonzados. La influencia de los primeros antropólogos evolucionistas es evidente; cita a John Lubbock, a Darwin y a Fitz Roy. Las páginas escritas por Barros Arana son, sin duda, un ejemplo clásico de la influencia del evolucionismo en Chile. Señala que "los fueguinos tienen el triste honor de ocupar el rango más bajo de la escala de la civilización" (1999:40), para agregar luego algo brutal, pero que nos sitúa en lo que era el contexto del pensamiento "culto" de esa época: "Bajo el punto de vista de sus costumbres y de su carácter, estas gentes tienen más relación con las bestias que con los hombres" (op.cit.:41). Cubre a los fueguinos de todos los atributos de la primitivez, de la falta de conciencia moral, de la primera escala en la evolución de la especie humana. 
La visión que Barros Arana tiene de los mapuches, tampoco es positiva. Les reconoce sagacidad para la guerra, pero señala que esas virtudes

"podrían hacer creer que sus facultades mentales habían adquirido un notable desarrollo" (ídem:) Pero, "el examen de su vida, de sus costumbres, $\mathrm{i}$ de su industria los coloca en un rango muy inferior. Los hábitos de ociosidad de la vida salvaje, el adormecimiento constante de aquellas facultades por la falta de actividad i ejercicio, los hacía incapaces de concebir nociones de un orden más elevado que la satisfacción de las necesidades más premiosas de su triste existencia, ni de comprender i apreciar cosa alguna que saliese del orden ordinario de sus ideas" (79).

Citando a Herbert Spencer, compara a estas agrupaciones humanas, a las cuales niega el nombre de sociedad, con los organismos animales inferiores en que todos los órganos desempeñan funciones biológicas semejantes, pero en que el individuo parece carecer hasta de vida propia (Idem: 80, nota al pie 2). En el análisis de las "supersticiones", sigue nuevamente la visión de Lubbock respecto a los orígenes de la civilización, comparando el estado salvaje de los mapuches chilenos, con el de comunidades primitivas de otros continentes.

El pensamiento de Barros Arana marcó generaciones de intelectuales chilenos. Sus aseveraciones se trasmitieron en los libros de historia de las escuelas, su influencia en la sociedad nacional es enorme y todavía permanece en la gente. Hasta el día de hoy se encuentran este tipo de citas en los libros de lectura ${ }^{15}$. Hay que tener en cuenta que Barros Arana estaba al tanto de la producción antropológica e histórica más moderna para su época. Ella lo condujo a un evolucionismo extremo, de ahí que observe a los indígenas chilenos cargados de primitivismo o barbarie. La idea de evolución cultural estuvo tan presente, que nunca fue criticada por nuestra sociedad. Desde entonces llegó para quedarse. Es por eso que el interés por rescatar una cultura así caracterizada era mínimo. Nadie después de leer al gran historiador podía tener un gran interés por los estudios etnológicos en Chile, salvo por mirar un fenómeno del mundo primitivo más puro. Es tal vez una de las razones por las que las ciencias antropológicas en Chile fueron tan tardías.

\section{El rescatismo}

Los estudios etnológicos de las primeras décadas del siglo XX tienen como objeto preservar los conocimientos y testimonios de las culturas originarias (e incluso campesinas tradicionales) que, según la visión de la época, estaban a punto de desaparecer. Se trataba de una labor de rescate. Esta es la primera etapa propiamente tal de la antropología en Chile y, como ya se ha dicho, está relacionada predominantemente con extranjeros. Los rescatistas saben que el desaparecimiento de los indígenas sería inevitable, pero intentan llamar la atención en el Estado chileno para que al menos esta extinción no fuera tan violenta ni sus memorias olvidadas. Como se comprenderá, es una visión museográfica de las culturas en extinción; el rescatista, va en busca de los últimos vestigios y los trata de depositar en un museo o en una publicación (generalmente de un museo), de modo de asegurar su recuerdo.

A comienzos del siglo XX don Tomás Guevara escribe Las últimas familias araucanas (1913) valiosísimo testimonio oral en que recoge los relatos de los viejos caciques de Arauco. Es uno de los primeros estudios de etnología propiamente tal. 
El Padre de Moesbach escribe su afamado Pascual Coña, Vida de un cacique araucano (1913), que es la primera "historia de vida" que se publica en el país, en el sentido de lo que hoy se entiende como tal en las disciplinas sociológicas y antropológicas. La motivación del informante y narrador, Pascual Coña, era dejar estampado aquellos conocimientos y tradiciones porque, pensaba y lo dice al Padre Moesbach, se van a perder y desaparecerán muy pronto (1984). Rodolfo Lenz en la lingüística y literatura, Ramón Laval y los iniciadores del estudio del folclore campesino o no indígena, tenían semejante sentimiento y por ello buscaban afanosamente a las personas que les podían relatar historias y cuentos, de modo de preservarlos para las generaciones futuras. En muchos sentidos tuvieron razón. Probablemente sea producto de esta conjunción de factores que surge la imagen del "sabio". Las ciencias antropológicas, en su variante principalmente arqueológica, adquieren tempranamente fama de actividades "cultas". Las personas que a ello se dedican son vistas por el resto de la sociedad como gente de "alta cultura", gran sabiduría, respeto consagrado.

Quizá a ello se debe también que estas disciplinas son cultivadas como "afición" por personas adineradas $\mathrm{y}$, muchas veces, ideológicamente relacionadas con la derecha o simplemente el establishment. En esta etapa de la disciplina, no se la percibe como una actividad perturbadora. Escapan a esta mirada puramente rescatista, algunos intelectuales que están ligados a corrientes antropológicas europeas de la mayor importancia en ese momento.

Ricardo Latcham, es un ingeniero inglés que llega a Chile contratado para la construcción de caminos y vías férreas. Su caso es paradigmático y se va a repetir muchas veces.
Lo que más le llama la atención es la presencia de indígenas por los lugares en que va y visita. Encargado de construir una vía en el sur de Chile, cerca de Loncoche, comienza a convivir con familias mapuche. Al parecer se alojaba en las casas (rucas) indígenas y se involucraba en su cultura. Al mismo tiempo, se hacía traer de Inglaterra la literatura antropológica que en esos primeros años del siglo XX, estaba siendo publicada de manera copiosa. Poco a poco, va a ir dejando la ingeniería de caminos y convirtiéndose en un "antropólogo a tiempo completo". Finalmente, será incorporado a la Royal Anthropological Asociation y conocerá a los afamados antropólogos de ese tiempo.

Habría mucho que decir de este prolífico autor, pero debemos señalar que a él le debemos una de las teorías más controvertidas de la antropología chilena, esto es, el origen de los mapuches. Latcham lanzó la hipótesis de la "cuña araucana". Consistía en que en tiempos poco definidos, pero muy anteriores a la invasión española, un grupo, banda, o como se quiera denominar, de belicosos guerreros junto a sus familias, habría migrado desde el centro sur de América, la llamada vertiente "tupi guaraní", cruzado las pampas, entrado por alguno de los boquetes cordilleranos y violentamente se habría incrustado en medio de una población indígena pre mapuche, de vida tranquila y laboriosa ${ }^{16}$.

El historiador Francisco Antonio Encina adhiere a esta teoría y la emplea en su voluminosa obra; de allí pasa a los textos escolares y se transforma hasta el día de hoy en la tesis no comprobada, ni comprobable más difundida, acerca del arribo de las poblaciones humanas al territorio que hoy ocupa Chile. Tomás Guevara (1922), criticó desde un inicio la tesis (1928:121-168; 1930:137-143), 
e incluso en el Congreso Mundial de Americanistas de Buenos Aires, la contradijo con pasión y, por cierto, con la aprobación de la mayor parte de los asistentes ${ }^{17}$. Esta tesis ha sido apropiada por los actuales mapuches de la vertiente argentina, quienes cuestionan las tesis que señalarían el origen mapuche en la vertiente del Pacífico y las migraciones posteriores hacia las Pampas, la denominada "araucanización de las Pampas". Una suerte de "contaminación" de los nacionalismos chileno y argentino sobre las identidades indígenas, juega una mala pasada en esta materia y resulta en la actualidad, altamente controvertida.

El caso más relevante es el de Martín Gusinde ${ }^{18}$, quien asistió al último período de vida de las sociedades canoeras y fueguinas del extremo sur del continente, dejándonose un testimonio inapreciable, ya que en el caso de los Selk'nam (conocidos como onas) la destrucción fue total, y entre Yagán (conocidos como Yámanas) y Kawésqar (conocidos como alacalufes) la reducción de su población ha sido casi completa. La obra de Gusinde es enorme y de gran valor. Se le ubica en el período clásico de los estudios antropológicos y etnológicos de Chile (1911-1940), junto al doctor Max Uhle, al ingeniero Ricardo Latcham y al director del Museo de Etnología y de Historia Natural, el doctor Aurelio Oyarzún. Gusinde colaboró en este museo y escribió varios artículos en sus publicaciones. Su obra es citada permanentemente por Lévi-Strauss y otros grandes antropólogos del mundo. Hay una publicación de los informes de los cuatro viajes que emprendió al sur, que constituyen uno de los mejores relatos etnográficos escrito en Chile sobre indígenas de este territorio. La gran obra Los fueguinos, publicada en alemán, solo ha sido traducida al español, en edición relativamente artesanal, en Argentina. Hace algunos años se realizó una importante exposición en la Biblioteca Nacional sobre la obra de Martín Gusinde y, existe la expectativa, de que sea traducido y publicado todo su trabajo.

Gusinde se relaciona con la corriente difusionista de la Escuela de Viena, Austria, país de dónde era originario. Discípulo de Schmidt va a ser enviado en una suerte de "misión científica". Gusinde era misionero del Verbo Divino, por tanto, el carácter desesperado de la investigación de Gusinde fue una suerte de "búsqueda de Dios". Si los seres que Darwin había dicho que eran los más primitivos del mundo, tenían o no conciencia de dios, era un asunto crucial. Por cierto que lo encontró y su principal conclusión fue que conocían a dios, la idea de dios y eran tan hijos de dios como cualquier mortal.

\section{El indigenismo en Chile}

Será recién a fines de la década del cincuenta que se iniciarán algunos estudios sobre asuntos étnicos bajo una perspectiva diferente. Se buscará interpretar la realidad histórica y presente de las culturas indígenas a la luz de las teorías contemporáneas de la antropología norteamericana y mexicana, principalmente. El cambio será notable. Por primera vez estos autores van a señalar que el mundo indígena, en este caso mapuche, no estaba en extinción, sino por el contrario "gozaba de muy buena salud". El estructural-funcionalismo dominaba en ese momento la antropología norteamericana y anglosajona, particularmente y el "relativismo cultural" se hacía espacios cada vez más definitivos. La antropología mexicana, al calor de la revolución indígena y campesina, "agrarista", se había encontrado con las teorías iniciales de esta nueva mirada antropológica. 
Manuel Gamio, discípulo de Franz Boas, había sido convocado a constituir el Instituto de Antropología e Historia de México; pocos años después de la revolución había escrito Forjando Patria, una suerte de manifiesto del indigenismo integracionista mexicano. En México el "rescatismo" cultural había sido mucho más importante, formándose museos de la talla del de Antropología en Chapultepec, uno de los más bellos e importantes del mundo. Los estudiantes de antropología y arqueología, al decir de Gonzalo Aguirre Beltrán, cumplían una suerte de apostolado patriótico, eran los encargados de organizar el "relato" de la revolución.

Los nombres de Louis Faron y Alejandro Lipschutz son, sin duda, centrales. Se inscriben en corrientes diferentes, pero congruentes. El primero, en la vertiente académica de la naciente ciencia antropológica universitaria norteamericana. EI segundo, en la antropología que acompaña al movimiento indigenista latinoamericano $y$, que tiene en México, su principal centro irradiador. El primero que llega y estudia la realidad chilena con el aparataje conceptual de la antropología moderna es Louis Faron, quien proviene de esa matriz disciplinaria y realiza estudios de campo en el sur de Chile. Su libro La estructura social mapuche aún es un clásico no superado. Fue traducido por el Instituto Indigenista Interamericano varios años después de su publicación en inglés, pero nunca ha sido publicado en Chile. Faron establece un compromiso vital con la sociedad mapuche, cosa que pocos antropólogos habían hecho. Al contrario de los estereotipos anteriores, Faron tiene una visión extremadamente profunda de los indígenas, ahondando en el tema del parentesco y haciendo una distinción entre la sociedad mapuche prereduccional y la sociedad mapuche posreduccional.
Al comparar el sistema de parentesco de la sociedad mapuche con una norteamericana, establece el concepto de "congregación ritual", donde se reúnen todos los lazos de parentesco de una comunidad. En lo económico, observa que los mapuches sufrieron un proceso de campesinización y que viven una economía de subsistencia.

La tesis central de Faron será que la sociedad mapuche no se encuentra en declive, ni menos en extinción, sino en una suerte de equilibrio. Se trata de una sociedad campesina, dominada, de subsistencia, pero que puede funcionar en la medida que tiene recursos culturales poderosos. $\mathrm{A}$ ello le denomina "moral". En una breve publicación en inglés, denominada Mapuche, sin pie de imprenta y probablemente de carácter de difusión, Faron tiene párrafos en que relata el gozo personal de "un día en la casa de Alonqueo". Este era un lonko de la comunidad de Roble Huacho, cercana a Temuco, donde Faron se alojaba. La descripción de esa fiesta, de la vida cotidiana, es notablemente hermosa y está lejana a la mirada conmiserativa de los evolucionistas, que consideraban a esas familias y personas, como primitivas o bárbaras (Faron, 1968; Alonqueo, 1967).

Sus trabajos posteriores no vinieron más que a reafirmar la calidad teórica y metodológica de este antropólogo. La mayor parte de estos trabajos no ha sido traducida al castellano y no están, como es obvio, disponibles ni siquiera para el público especializado.

El indigenismo, por otra parte, tuvo su bautismo en la reunión de Pátzcuaro convocada por el entonces presidente de México, Lázaro Cárdenas, en 1940. Allí se sistematiza el pensamiento prodefensa del indígena de un sector de la intelectualidad latinoamericana. Los antropólogos de la época reinterpretan lo que en literatura estaban 
haciendo Ciro Alegría, Rosario Castellano, Jorge Icaza y tantos otros escritores indigenistas de la época y que en la pintura se expresaba en Rivera, Siqueiros y los muralistas. Don Alejandro Lipschutz, nacido en Letonia en 1883, es la voz más fuerte en Chile de esta corriente. Su defensa de la comunidad indígena hoy tiene plena validez en el pensamiento latinoamericano y su percepción de la óptica de análisis de la cuestión mapuche, se ha comprobado sumamente apropiada. Lipschutz proviene de las ciencias naturales, de la medicina específicamente, y su incursión en la etnología lo conduce a las ciencias humanas, pero no lo liga a la sociología o a las ciencias sociales, que en ese momento emergen como disciplinas autónomas en Chile.

El gran aporte hasta el día de hoy del pensamiento de Lipschutz, consiste en el concepto de "autonomía indígena" (1956, 1963). Pensaba que los mapuches debían constituirse en una república autónoma. En algunos artículos de periódicos postulaba una suerte de parecido con los cantones suizos. Como marxista y buen conocedor de las teorías de las "nacionalidades" de Lenin y otros dirigentes rusos, interpretó en esa línea la cuestión indígena. Como se recordará, uno de los grandes temas de los bolcheviques consistía en incorporar a las "nacionalidades" no rusas a la revolución. En la ciudad de Bakú, hoy capital de Aserbaiyán, fue donde se realizó la conferencia que aunó a las "nacionalidades" islámicas, dependientes del Imperio Ruso, con las luchas del proletariado de San Petersburgo y Moscú. Lo mismo ocurrió con los estados bálticos de dónde provenía nuestro sabio. Por ello, no le parecía disparatado proponer "la República Independiente Araucana". A pesar de esta propuesta, que tiene una vigencia polémica evidente, los partidos socialistas y comunistas no hicieron suyo este pensamiento. Se le reconoció, de todas formas, ser la principal figura del indigenismo de izquierda en Chile y el día en que Salvador Allende firmó la Ley Indígena (1972), se encontraba sentado a su lado con su larga barba blanca.

\section{La antropología académica}

Muy lentamente la antropología se abre paso en el mundo académico. Iniciándose la década del sesenta, la Universidad de Chile dominaba en forma absoluta las humanidades. En esos años pasaban por la capital del país, rumbo a lugares de estudios de campo, numerosos antropólogos de diferentes nacionalidades y tendencias. Luis Oyarzún, profesor de estética en la Universidad de Chile, luego decano y rector subrogante, jugó un papel importante como anfitrión culto de muchos de estos vistantes, como Joseph Emperaire, a quien ayudó para su traslado a Puerto Edén donde realizó el estudio sobre los Kawésqar. Por otro lado, la necesidad de formar arqueólogos profesionales era cada vez más evidente, por lo que se establece un Instituto en el Pedagógico de la Universidad de Chile.

Hasta ese momento, mediados de los años sesenta, la naciente arqueología estaba situada en el ámbito de las ciencias naturales. Ricardo Latcham, Alejandro Lipschutz, Louis Faron, Grete Mostny, y tantos otros, no aparecían involucrados con las ciencias sociales ni con los científicos sociales que iban surgiendo en aquellos años. Más bien, su campo de actividad se acercaba al de las ciencias naturales. No es por casualidad que el principal espacio de acogida haya sido el Museo de Historia Natural de la Quinta Normal. En ese museo se alojaron las colecciones de pájaros, plantas, piedras del país y, también, los hallazgos encontrados por los arqueólogos. 
A la entrada de este museo se encontraba una cripta de cristal donde estaba depositado el niño momificado encontrado en el entierro de altura del Cerro El Plomo. Ese niño, posiblemente incaquechua, parecía, en la mentalidad de la época, ser parte de la naturaleza de este país, en una extraña consideración acerca de lo que fueron sus culturas antiguas. En Chile no había ni hay Museo del Hombre", ni "Museo Antropológico" o, alguna denominación que nos hiciera recordar la necesaria separación entre "naturaleza y cultura". La arqueología había comenzado a desarrollarse desde varios años atrás, producto de la acción de sociedades privadas que reunían a los arqueólogos aficionados y creaban un ambiente de mayor rigor científico. Finalmente se crea en la Universidad de Chile el Instituto de Investigaciones Antropológicas, que reúne a personas como Alberto Medina, Carlos Munizaga, Francisco "Pocho" Reyes, Juan Munizaga, Bernardo Berdichewsky, Lautaro Nuñez y otros que, proviniendo de otros campos y profesiones, se inician en la antropología muy combinada con la arqueología.

Uno de los primeros que se define como antropólogo social y quizá el fundador de la antropología moderna en Chile, es don Carlos Munizaga Aguirre. Abogado de origen, sigue los estudios de Sociología en la reciente creada Facultad Latinoamericana de Estudios Sociales (FLACSO). Por un lado, tiene la influencia de Merton, que dominaba en esos días la sociología, y de Metraux, a quien conoce en sus viajes a Chile y prologa su primer libro. Le interesa el tema de la migración mapuche a Santiago que, en ese momento, era muy masiva. Muestra que, al llegar a Santiago, se produce una situación de alta complejidad; siguiendo las teorias de la época, lo denomina como una suerte de "anomia", una actitud que la entiende como cierto grado de psicosis.
Su estudio se concentra en la Quinta Normal de Santiago y sus alrededores, en los que cada domingo los migrantes mapuches se reunían y compartían. A este conjunto de situaciones les denominó "estructuras transicionales" y constituye un importantísimo estudio que inaugura, por decir lo menos, la antropología urbana en Chile (Munizaga, 1967).

En ese mismo lugar, conoce a un joven estudiante mapuche de Puerto Saavedra, Lorenzo Aillapan, con quien elabora su "Historia de Vida". Este trabajo es quizá la primera biografía antropológica moderna en el país (1960). Como es bien sabido, don Lorenzo Ayllapán es hoy en día uno de los intelectuales y poetas más destacados del mundo mapuche.

A partir de estos estudios sobre migraciones mapuche, Carlos Munizaga se introduce en el tema psiquiátrico e investiga sobre los problemas de alcohol, mapuches alienados, violencia y familia (1987, 1966-1967). Aunque el desarrollo de estos temas es inicial, Munizaga puso sobre la mesa un tema que hoy es de una evidencia casi indiscutible, la existencia de cuestiones culturales en las denominadas "enfermedades mentales" y que para aquel entonces resultaba de una enorme importancia.

En la década de los sesenta, el Instituto de Investigaciones Antropológicas de la Universidad de Chile, se dedica fundamentalmente a la arqueología y a estudios muy limitados de Antropología Social, como los señalados de Munizaga. Mario Orellana fue, tal vez, el gestor de mayor importancia en esos años, impulsando programas de becas para la formación de jóvenes antropólogos, entre los cuales el autor de estas líneas obtuvo una beca en el año 1969-1970; aunque era evidente que la antropología no tenía aún, en el medio universitario, un campo propio. 
Por la misma época, pero en el Centro para el Desarrollo Económico y Social de América Latina (DESAL), un importante centro de pensamiento de Santiago, Ismael Silva Fuenzalida aporta la mirada antropológica para la comprensión de la marginalidad $(1966,1967)$. Silva Fuenzalida, de quien el autor de estas líneas fue ayudante, incorpora a la discusión de la época una extensa bibliografía de antropólogos norteamericanos y europeos que estaban preocupados por los problemas del desarrollo. George Foster, Charles Erasmus, Eric Wolf, Ruth Benedict, Raymond Firth, Lucy Mair, entre otros. Casi treinta años después surgieron en el país los mismos temas bajo el rótulo de "estudios de pobreza" y no son pocos los que vuelven a observar los aspectos culturales de la pobreza como esenciales a la perduración de esas condiciones.

En el sur, Milan Stuchlik había iniciado un estudio sistemático sobre la sociedad mapuche en la naciente Escuela de Antropología de la Universidad Católica de Temuco, conformando una de las pocas "escuelas" en estas materias. Milan realizó trabajo de campo y observó la enorme cantidad de sistemas de intercambio que poseían las familias mapuches. Estos intercambios, que no pasaban por el mercado, bajo la forma de "medierías", Ilamaron la atención del investigador y lo llevaron a plantear importantes hipótesis sobre la red de soportes que poseía la sociedad mapuche contemporánea. Alcanzó a publicar en Chile un pequeño libro en las Ediciones de la Universidad Católica. Su obra posterior fue publicada en el extranjero.

Algo semejante ocurría en la Universidad de Concepción, donde se habían iniciado investigaciones relacionadas con las transformaciones que se estaban produciendo en el sur del país.
Alejandro Saavedra, publica en 1972 una investigación iniciada en el Instituto de Capacitación e Investigación en Reforma Agraria (ICIRA) sobre los mapuche. Es de gran interés, ya que constituye uno de los pocos documentos empíricos con datos fidedignos, acerca de la situación económica y social de los mapuche en ese período. Saavedra observa una sociedad mapuche escindida en sectores que se enriquecen y otros que se pauperizan, provocándose muchas veces rupturas en las solidaridades internas. Posiblemente, una década de apoyo estatal a los pequeños propietarios campesinos-indígenas, había provocado esa diferenciación interna de la sociedad indígena. Las investigaciones iniciadas en ese ámbito, los trabajos de José Luis Najenson y algunos otros antropólogos argentinos, se vieron interrumpidas en el año 1973 por los sucesos que lo acompañaron.

En Chile, la aparición pública de la cuestión étnica propiamente tal ocurre recién en la década del setenta y, más propiamente, a partir del año 1978, en plena Dictadura Militar, como consecuencia del intento de división de las comunidades mapuche. Cristián Vives fue probablemente quien denunció de manera más clara este intento de etnocidio en las páginas de la revista Mensaje. Durante la década del cincuenta, el movimiento indígena tuvo cierta relevancia, pero se manifestó exclusivamente en un terreno culturalista, lo cual permitió que fuera procesado por parte de la sociedad chilena y sus intelectuales, como un exclusivo asunto de folclore. Con esta visión, se reafirma la vieja concepción de que lo étnico era algo pasado, un asunto de la historia. En los años cincuenta, el indigenismo se relaciona con los intentos populistas del general Carlos Ibañez del Campo, 
quien de una u otra manera apoya algunas demandas procesadas por la organización mapuche denominada Corporación Araucana. En la década del sesenta, el asunto indígena fue visto con ojos campesinos. Se entendió al indígena como un campesino pobre que debía ser incorporado a las movilizaciones revolucionarias que debían cambiar la estructura del agro-chileno: la reforma agraria. Se reaccionó contra la visión del indigenismo, no considerando los aspectos étnicos de este sector de pequeños agricultores. Una excepción fue el antropólogo brasileño Wilson Cantoni (1972a, 1972b), quien escribe varios trabajos sobre los asuntos mapuche, adoptando una posición intermedia. Si bien critica el indigenismo populista de la década del cincuenta, valora los aportes que realizó, en especial, su intento de readaptar la identidad étnica estableciendo una suerte de alianza con el Estado. La mayor parte de los estudios iban, sin embargo, por otro lado, ya que se enfocaban casi exclusivamente en la necesidad de desarrollar a este empobrecido sector del país, incorporándolos a las reformas estructurales.

El golpe de Estado rompió la incipiente antropología que en los años anteriores se había desarrollado en las universidades. Se cerraron casi todas las escuelas con excepción de la Universidad de Chile; allí permanecía la vieja idea folclorizante de la antropología que no iba en contra ni del nuevo modelo autoritario, ni cuestionaba cosa alguna. El año 1975/76 comenzaron a salir jóvenes con ese título profesional. Salvo Mario Orellana, arqueólogo y querido profesor, que en medio de complejos procesos políticos, fue expulsado de la universidad, el resto se mantuvo impertérrito repitiendo viejas monsergas de la antropología acrítica.

\section{Nuevas tendencias}

La crisis de 1973 afectó, como es bien sabido, todos los ámbitos del país y, obligó a plantearse cuestiones que habían estado vedadas o ignoradas. Una de ellas fue la certeza de la mencionada homogeneidad étnica de la sociedad chilena. Muchos intelectuales y chilenos corrientes debieron viajar al exilio y mirar desde el extranjero, con otros ojos, su sociedad. La tal mentada "blancura" de la sociedad chilena, era puesta en relativa comparación en las frías calles de Oslo o Amsterdam. Allí se percibía con una fuerza desconocida el mestizaje nacional. Se valoraba de una manera distinta el asunto de "las raíces" de la nacionalidad.

A fines de la década del setenta, en el sur de Chile, se reinicia un movimiento indígena de fuerte contenido étnico. Numerosos intelectuales se ligan a este movimiento $y$, desde las organizaciones no gubernamentales, realizan estudios, investigaciones y tareas de acompañamiento. Coincide con la aparición del tema en toda América Latina, e incluso en otras partes del mundo. Las disciplinas ligadas a la temática indígena van adquiriendo una suerte de entidad que antes no era conocida. Se ligan por primera vez a las ciencias sociales, al pensamiento crítico, a la sociología y a la política. Intentan salir del ámbito del folclore, de la vieja discusión historiográfica, del círculo vicioso de los estudios neutros y sin consecuencias prácticas, a los que la etnografía había sido reducida en muchos círculos academicistas.

La cuestión étnica tiende a incorporarse a la cuestión social, a los grandes temas de la política nacional. Hoy, se podría afirmar, que el asunto indígena es parte de la agenda de los grandes temas que deben ser abordados por el conjunto de la sociedad. 
Hoy, se podría afirmar, que el asunto indígena es parte de la agenda de los grandes temas que deben ser abordados por el conjunto de la sociedad. Se ha sacado la cuestión étnica del puro folclore, de la controvertida y estéril historiografía tradicional, de los asuntos meramente agrarios, campesinos, y ha adquirido una cierta especificidad. Es evidente que es un proceso inacabado, pero pareciera que el hecho es irreversible.

A comienzos del siglo XX, la "cuestión indígena" no se asocia en ningún momento a la denominada "cuestión social", tema central de la intelectualidad progresista de la época. Como es bien sabido, esta discusión será la que definirá por casi un siglo la problemática social en Chile. Allí estará el tema de la clase obrera, de la pobreza, de la ruralidad, de la salud y la educación de las masas populares. Por tanto, en la temática social, en los temas a legislar, en la cuestión del "cambio social" y, más adelante, en los asuntos "del desarrollo" no estará presente la cuestión étnica. Esto será válido, a lo largo del siglo, tanto para las corrientes conservadoras como para las progresistas. Muchas veces serán estas últimas las que menos comprenderán la perspectiva indígena e indigenista, considerándola conservadora, atrasada, fruto de la nostalgia y sin sentido de evolución y progreso. Es por ello que el comportamiento electoral, político, y las adscripciones indígenas a la política chilena serán bastante erráticas y, en general, más marcadas al conservadurismo, al voto de derecha. Esta separación entre ambos asuntos, lo étnico y lo social, es lo que a nuestro modo de ver explica de manera más profunda el carácter de la antropología en Chile, su remanente conservador y acrítico, sus dificultades para salir de su matriz folclórica, museográfica, coleccionista y conservadora.
En las últimas décadas esta mirada cambió radicalmente, no tanto por una transformación de los paradigmas de la antropología, sino por la "rebelión del sujeto indígena", quien de ser un personaje observado, se transformó en un activo sujeto observador. Los procesos de descolonización cambiaron la temática antropológica. La exclusividad de lo étnico en la antropología, tanto en Chile como en otras partes, dejó de ser monopolio. Otros actores sociales se incorporaron al "corpus". Campesinos, jóvenes, pobladores y pobres de la ciudad, sobre todo "las mujeres" y, luego, los "estudios de género"19. La aparición posterior de los "estudios culturales" afectó también fuertemente a la antropología. Cultura, gestión cultural, patrimonio, en fin, se produjo una explosión de temáticas, aunque por la herencia y quizá inercia temática, la cuestión étnica sigue siendo la especialidad propia de la antropología, en este caso chilena, y la que la diferencia de disciplinas tales como la sociología, ciencia política o estudios culturales.

Lo que ha ocurrido con la antropología en las últimas décadas es asunto muy cercano y debería ser objeto de otro trabajo. Solamente señalar que al día de hoy existen en Chile varias escuelas de antropología donde se gradúan jóvenes llenos de entusiasmo por descubrir en el pasado y en el presente, nuevas perspectivas sociales, políticas y culturales para nuestra sociedad. Los desafíos son grandes y a veces abrumadores. 


\section{Notas}

${ }^{1}$ Este artículo se origina en los apuntes de clase del curso "La Antropología en Chile" dictado en la Escuela de Antropología de la Universidad Academia de Humanismo Cristiano, Santiago de Chile, durante los últimos 15 años. Muchas de las ideas que acá están volcadas se produjeron en el diálogo con los estudiantes o en trabajos que estos hicieron sobre temas específicos, siendo muy difícil conocer su procedencia. La antropóloga Magaly Mella, hace ya años transcribió algunos apuntes de clase, de los que he tomado referencias parciales.

${ }^{2}$ Hay una discusión referida a la fecha ya que otra publicación señala que: "El 21 de Septiembre de 1911 se reunieron en los salones de la Biblioteca Nacional 72 personas y la reunión fue presidida por don Tomás Guevara Silva, naciendo de ese encuentro la Sociedad Chilena de Historia y Geografía". Índice de la Revista Chilena de Historia y Geografía, publicado por la Sociedad Chilena de Historia y Geografía, desde el número 1 al 150.

${ }^{3}$ Rodolfo Lenz, alemán, establecerá el sistema de transcripciones del período (el "grafemario universal", y la transcripción a dos columnas). Impregnará, además, el ambiente intelectual de la idea germana de que la investigación del conocimiento del pueblo ("Folclore") tiene un valor patrimonial en sí misma. Esta idea va a ser seguida por folcloristas muy conocidos en Chile, tales como Margot Loyola, Violeta Parra y otros.

${ }^{4}$ Su primera edición, en inglés, fue publicada en 1976.

${ }^{5}$ Muchas de las ideas expresadas en este artículo pueden estar contaminadas por el trabajo de Geertz, "The integrative revolution: primordial sentiments and politics in the new states". En Geertz, C. (ed.) (1963). Old societies and new states: the quest for modernity in Asia and Africa. New York: The Free Press of Glencoe \& London/UK: Collier-Macmillam, pp.105-157.

${ }^{6}$ La misma idea de "historia ancestral" es muy discutible. Hay quienes siempre ven en las tradiciones un discurso construido desde la época presente, como una lectura interesada del pasado. Sobre este tema, hemos analizado la construcción del discurso indígena en América Latina en los últimos años, demostrando que se trata de una fusión de contenidos de diversa procedencia, los cuales son reunidos como "tradicionales" o "ancestrales" y adquieren una enorme eficiencia en función de la obtención de los objetivos indígenas. Ver: Bengoa, (2007) [2000]; Hastings (2000).

${ }^{7}$ El Estado chileno tuvo una enorme capacidad de aunar voluntades en torno a su proyecto civilizatorio. Desde el siglo XIX se construye un discurso sólido en torno a su capacidad de dominar la sociedad, de doblegarla a sus intereses, de cooptar cada una de sus partes en función del proyecto colectivo. Esa fuerza discursiva del Estado condujo a la ciudadanía a autoidentificarse con la patria y la nación. Como pocas sociedades, la chilena fue patriotera en lo más profundo. No hubo necesidad de predicar el nacionalismo, ya que todos los habitantes lo practicaban de manera entusiasta. Los partidos e ideologías de derecha e izquierda fueron profundamente nacionalistas. Es cosa de leer los poemas de nuestros más insignes poetas izquierdistas o, de cualquier posición ideológico-política, para percibir un discurso de confianza, casi ciega, en la capacidad civilizadora del Estado y las bondades sin parangón del hecho de "ser chileno". El período democrático presidencialista del siglo $\mathrm{XX}$, inaugurado por Arturo Alessandri Palma y culminado con Salvador Allende Gossens, estuvo marcado por ese denominador común: un discurso nacional e incluso nacionalista no discutido, un discurso homogeneizador de la sociedad chilena. Los chilenos se vieron a sí mismos sin diferencias étnicas, sociológicas, culturales. Un chileno de Arica hablaba con el mismo tono y sonsonete de voz y consideraba pensar del mismo modo, que uno de Temuco o Punta Arenas. Las diferencias se referían a la manera de ocupar el aparato estatal, para llevar a cabo los diferentes proyectos ideológicos que cada cual poseía. Todos eran chilenos patriotas de derecha, centro o izquierda.

${ }^{8}$ Don Francisco Antonio Encina, al iniciar cada capítulo de su enorme Historia de Chile, dedica páginas y páginas a explicar las características psicológicas del personaje eje de ese período histórico. No pocas veces esas características obedecen al origen de sus ancestros, caso de Arturo Prat, quien habría llegado a esos niveles de heroicidad por su origen catalán mediterráneo y, no pocas veces, se argumenta en aspectos psicofísicos 
y psicoraciales de los personajes involucrados, como forma de explicar las conductas que les cupo tener en la historia. Encina, F.A. (1949). Historia de Chile. Desde la Prehistoria hasta 1891.Santiago: Editorial Nascimento.

${ }^{9}$ La Historia del Reyno de Chile del Padre Diego de Rosales, S.J., es la expresión del cambio en la forma y estilo de escribir los relatos sobre el país. Antes de Rosales son crónicas en el sentido más tradicional del término. Rosales, Diego de. (1991). Historia General del Reyno de Chile, Flandes Indiano. Santiago: Editorial Andrés Bello. Santiago. 1991.

${ }^{10}$ Ver la edición moderna y crítica de Mario Ferreccio Podestá y Raissa Kordic Riquele. Dos Tomos. Santiago: Ril Editores. 2001. En esta edición se publica el texto y la "Suma y Epílogo" que habría sido escrita también por el soldado cautivo.

${ }^{11}$ Además de la Crónica, hay varios géneros literarios que se ocupaban en la época de la Conquista, siendo el mas conocido el que utilizó Ercilla y Zúñiga, que sigue la línea de los poemas épicos. Se ha discutido largamente el valor histórico de La Araucana. Cada cierto tiempo, hay quienes ponen en duda su valor $y$, otros, que apuestan por sus precisas descripciones de lugares y hechos. Ercilla, debemos recordar, vino a Chile con las tropas de Hurtado de Mendoza y recorrió el territorio del sur, hasta incluso cruzar a la Isla Grande de Chiloé. Sus conversaciones con los soldados antiguos de la Conquista de Chile, seguramente le fueron dando un panorama de cómo eran los indígenas, a quienes conoció directamente en las batallas. Las fuentes de Ercilla eran lo que se contaba en la pequeña colonia española que había quedado en Chile después de la derrota de Tucapel donde Valdivia fue derrotado y muerto. Si el lector cuidadoso tiene la precaución de comprender este punto de vista, podrá sacar mucho provecho histórico del afamado poema. El lector crítico deberá recordar que Ercilla escribe sus versos vuelto a España muchos años después, cuando ya la memoria ha seleccionado los hechos y no hay testigos a quienes preguntarles. En su imaginación de poeta, va combinando de modo libre y, sin duda inspirado, las imágenes habituales del estilo literario con los recuerdos de la tierra que había visitado. Junto a ensalzar las armas españolas, sentido central del poema, ensalza a sus enemigos, ya que en la braveza de unos reside la valentía de los otros. Leídos estos textos con esa prevención crítica, se pueden ir abriendo llenos de referencias, no tanto a la realidad de los indígenas, sino a lo que los españoles de esa época en Chile, contaban de lo que eran, quienes eran y, qué hacían los indígenas. Se puede ver que algunas de las descripciones son de enorme detalle y propias de quien estuvo en el terreno. Cuando Ercilla describe la batalla de Tucapel, no cabe duda que está señalando un lugar preciso. El verso señala que se escucha el mar al fondo, está la montaña, las ciénagas de la laguna de Lanalhue. Hoy en día, quien camine por ahí, pese a los enormes cambios que hay en el paisaje, puede comprender que el poeta está dando referencias muy precisas. El lugar, cercano al actual pueblo de Cañete, puede ser determinado con precisión.

12 Veáse este tema más en detalle en Bengoa, J. (1992). Conquista y Barbarie, Santiago: Editorial Sur. Junto al ya citado Historia de los antiguos mapuches del sur. La obra del Padre Luis está dispersa en cartas, gramáticas, cancioneros religiosos, en fin, un material que aún no se ha recopilado más que parcialmente.

${ }^{13}$ Existen múltiples ediciones; la más conocida es de la Editorial Francisco de Aguirre, Santiago y Buenos Aires. Edición de 1972 y del 2003. La mayoría de estos textos se encuentran disponibles en: http://www. memoriachilena.cl

${ }^{14}$ Lastarria está en el origen de esta generación de intelectuales que, a mediados del siglo XIX, comenzarán a "pensar en americano/chileno". La Guerra con España, ocurrida en la década del cincuenta de ese siglo, será determinante para esta generación que producirá sus obras a fines del siglo.

${ }^{15}$ Véase nuestro estudio sobre la enseñanza de la historia indígena en los colegios y los conocimientos requeridos para rendir la Prueba de Aptitud Académica (examen para el ingreso a la Educación Superior universitaria, vigente hasta el 2002, reemplazada por la Prueba de Selección Universitaria, PSU), "La conquista vulgar". Revista Tópicos 1, Santiago, 1990.

${ }^{16}$ Guillermo Krumm publicó en la Revista Chilena de Historia y Geografía, un trabajo minucioso relatando el recorrido hecho por este grupo propiamente "araucano". 
Es obviamente una fantasía curiosa. Ver del autor: "División territorial de la Araucanía". RCHHG. №139, 1971, pp. 86-104; №140, pp. 50-71.

${ }^{17}$ Dillman Bullock, un pastor metodista norteamericano que llegó a la Misión de El Vergel, cerca de Angol en las primeras décadas del siglo veinte, encontró decenas de entierros mapuches en vasijas de barro. Construyó uno de los museos más ricos del sur de Chile. Impresionado por la laboriosidad, sedentarismo y agricultura de esa sociedad, la "cultura El Vergel", les denominó "Kofqueches", gente del pan. Era tan dominante la opinión de Latcham que no se atrevió a contradecirlo, ni menos señalar, que ese pueblo cuyos vestigios observaba, era pacífico. Por lo tanto, debió señalar que se trataba de un pueblo no mapuche, anterior a aquel y que fue dominado violentamente por unos guerreros que venían del otro lado de la cordillera. Por cierto, que hoy en día, no existe alguien que niegue que esos kofqueches o "del Vergel" eran tan mapuches como todos quienes habitaban desde el Valle del Choapa hasta Chiloé. Bullock, D. (1967). La agricultura de los mapuches en los tiempos pre hispánicos. Temuco: Imprenta Alianza.

${ }^{18}$ Martín Gusinde, (1886-1969), llega a Chile en 1912, a la edad de 35 años, enviado por la orden del Verbo Divino. Trabajó en tareas docentes en el Liceo Alemán. Hizo cuatro viajes a la Tierra del Fuego, en 1918, 1920, 1921 y 1922-1923, a partir de los cuales entrega cuatro informes a la Revista del Museo de Etnología y Antropología en Chile. Gusinde, M. (2003) Expedición a la Tierra del Fuego. Santiago: Editorial Universitaria.

${ }^{19}$ La explosión de temas ha sido muy grande. Tantos, que no es posible mencionarlos en este espacio.

\section{Referencias bibliográficas}

Alonqueo, M. (1967). Instituciones religiosas del Pueblo Mapuche. Santiago/Temuco: Ediciones Nueva Universidad.

Bengoa, J. (2007) [2000] La emergencia indígena en América Latina. Santiago: Fondo de Cultura Económica. (1990). "La conquista vulgar". Tópicos 1, Santiago de Chile.
Bullock, D. (1967). La agricultura de los mapuches en los tiempos prehispánicos. Temuco: Imprenta Alianza. Cantoni, W. (1972a). "Fundamentos para una política cultural mapuche". Cuadernos de la Realidad Nacional, №14. Universidad Católica de Chile, pp. 74-96

(1972b) Relaciones del mapuche con la sociedad chilena. Santiago: Escuela Latinoamericana de Sociología.

Chapman, A. (2012). Yaganes del Cabo de Hornos. Encuentros con los europeos antes y después de Darwin. Santiago: Editorial Pehuén.

Colegio de Antropólogos de Chile (1985). Actas del primer congreso de antropología.

Encina, F.A. (1949). Historia de Chile. Desde la Prehistoria hasta 1891.Santiago: Editorial Nascimento. Faron, L. (1968). The Mapuche Indians of Chile. Nueva York: Holt Rinehart and Winston.

Geertz, C. (1963). "The integrative revolution: primordial sentiments and politics in the new states". En Geertz, C. (ed.). Old societies and new states: the quest for modernity in Asia and Africa. New York: The Free Press of Glencoe \& London/UK: Collier-Macmillam, pp.105-157.

Gonzalez de Nájera, A. (1971). Desengaño y reparo de la Guerra de Chile. Edición facsimilar de la Colección de Historiadores de Chile. Santiago: Editorial Andrés Bello. Guevara, T. (1928). "Sobre el origen de los araucanos". Réplica a Don R. Latcham. En: RCHHG, №63, pp. 121-168

RCHHG, Número 68. 1930. pp. 137-143.

Guevara, T. (1913). Las últimas familias araucanas. Santiago: Imprenta y Litografía Barcelona.

Gusinde, M. (1951). Hombres primitivos de la tierra del Fuego. Sevilla: Escuela de Estudios Hispanoamericanos (1982). Los indios de la Tierra del Fuego. Vol.: 1, 2, 3, y 4. Buenos Aires: Centro Argentino de Etnología Americana.

Hastings, A. (2000). La construcción de las nacionalidades. Cambridge University Press.

Krumm, G. (1971). "División territorial de la Araucanía". RCHHG. №139, pp. 86-104; №140, pp. 50-71.

Latcham, R. (1922). La organización social y las creencias religiosas de los antiguos Araucanos. Santiago: Museo de Etnología y Antropología de Chile. 
Lipschutz, A. (1956). La comunidad indígena en América y Chile. Santiago: Editorial Universitaria. (1975) [1963]. El problema racial en la conquista de América y el mestizaje, México: Editorial Siglo XXI.

Medina, J.T. (1882). Los aborígenes de Chile. Santiago: Imprenta Gutemberg. Reproducción facsimilar en www. memoriachilena.cl

Moesbach, E.W. (1984). Pascual Coña: Vida y costumbre de los indígenas araucanos en la segunda mitad del siglo XIX. Santiago: Pehuén

Munizaga, C. (1960). Vida de un Araucano. El estudiante mapuche L. A. en Santiago de Chile, en 1959. Santiago: Centro de Estudios Antropológicos de la Universidad de Chile.

(1961). Estructuras transicionales en la migración de los araucanos de hoy a la ciudad de Santiago de Chile. Santiago: Centro de Estudios Antropológicos de la Universidad de Chile.

(1966-1967). "Enfoque antropológico psiquiátrico de indígenas mapuches alienados" Antropología. Años IV y V. Vol. 4, pp 3-16.

(1987). "Aportes etnográficos al estudio de organizaciones psiquiátricas". Revista Chilena de Antropología. №6, pp. 27-35.

Nuñez de Pineda y Bascuñán, F. (2001) El Cautiverio Feliz. Colección de Historiadores de Chile. Edición de Diego Barros Arana. Edición moderna y crítica de Mario Ferreccio Podestá y Raissa Kordic Riquele. Dos Tomos. Santiago: Ril Editores.

Poeppig, E. (1956). Un testigo en la alborada de Chile. (1826-1829) Santiago: Editorial Zigzag.

Sociedad Chilena de Historia y Geografía. (1986). Indice de la Revista Chilena de Historia y Geografía. №1 al 150. Santiago: Editorial Andrés Bello.

Rosales, Diego de. Historia General del Reyno de Chile, El Flandes Indiano. (1991). Santiago: Editorial Andrés Bello.

Saavedra, A. (1972). La cuestión mapuche. Santiago: ICIRA.

Sarmiento, D. F. (1947). Facundo. Círculo Literario de Buenos Aires.

Silva Fuenzalida, I. (1966). "Strategic elements in the revolution of rising expectations in Latin America"
(Communication submitted to the 6th World Congress of Sociology, Evian, France, 4-11, Sept. 1966) Santiago: DESAL.

(1967). "La marginalidad indígena chilena: una visión antropológica”. Mensaje, №160, pp. 281-287.

(1969). Marginalidad en América

Latina. Un Ensayo de Diagnóstico. Barcelona: Editorial Herder

Smith, E. R. (1972) [1885]. "Los Araucanos". En Imágenes de Chile. (Trad. de R. Latcham). Santiago: Editorial Nascimento.

Stuchlik, M. (1999). La vida en mediería. Mecanismos de reclutamiento social de los mapuches. Santiago: Soles Ediciones

Treutler, P. (1958). Andanzas de un alemán en Chile. 1851-1863. (Trad. de C. Keller). Santiago: Editorial del Pacífico. 